\title{
Socio-demographic factors associated with smoking and smoking cessation among 426,344 pregnant women in New South Wales, Australia
}

\author{
Mohammed Mohsin*†1 and Adrian E Bauman ${ }^{\dagger 2}$
}

Address: ${ }^{1}$ Biostatistician, Centre for Research, Evidence Management \& Surveillance, Division of Population Health, Sydney South West Area Health Service, Liverpool BC, NSW 1871, Australia and 2Professor of Public Health \& Epidemiology, School of Public Health, University of Sydney \& University of New South Wales, Australia

Email: Mohammed Mohsin* - m.mohsin@unsw.edu.au; Adrian E Bauman - adrianb@health.usyd.edu.au

* Corresponding author †Equal contributors

Published: 2I December 2005

BMC Public Health 2005, 5:138 doi:10.1/186/147/-2458-5-138

This article is available from: http://www.biomedcentral.com/I47/-2458/5//38

(C) 2005 Mohsin and Bauman; licensee BioMed Central Ltd.

This is an Open Access article distributed under the terms of the Creative Commons Attribution License (http://creativecommons.org/licenses/by/2.0), which permits unrestricted use, distribution, and reproduction in any medium, provided the original work is properly cited.
Received: 0I August 2005
Accepted: 21 December 2005

\begin{abstract}
Background: This study explores the socio-demographic characteristics of pregnant women who continue to smoke during the pregnancy, and identifies the characteristics of the smokers who were likely to quit smoking during the pregnancy period.

Methods: This was secondary analysis of the New South Wales (NSW) Midwives Data Collection (MDC) 1999-2003, a surveillance system covering all births in NSW public and private hospitals, as well as home births. Bivariate and multiple logistic regression analyses were performed to explore the associations between socio-demographic characteristics and smoking behaviour during pregnancy.
\end{abstract}

Results: Data from 426,344 pregnant women in NSW showed that $17.0 \%$ continued to smoke during pregnancy. The smoking rate was higher among teenage mothers, those with an Aboriginal (indigenous) background, and lower among more affluent and overseas-born mothers. This study also found that unbooked confinements, and lack of antenatal care in the first trimester were strongly associated with increased risk of smoking during pregnancy. About $4.0 \%$ of the smoking women reported they may quit smoking during their pregnancy. Findings showed that mothers born overseas, of higher socio-economic status, first time mothers and those who attended antenatal care early showed an increased likelihood of smoking cessation during pregnancy. Those who were heavy smokers were less likely to quit during pregnancy.

Conclusion: Although the prevalence of smoking during pregnancy has been declining, it remains a significant public health concern. Smoking cessation programs should target the population subgroups of women at highest risk of smoking and who are least likely to quit. Effective antismoking interventions could reduce the obstetric and perinatal complications of smoking in pregnancy.

\section{Background}

The harmful effects of smoking during pregnancy was first investigated by Spontag and Wallace in 1935 [1]. They reported 'a definite and real' increase in fetal heart rate 
after the mother began to smoke. Since then there is clear evidence of risks associated with smoking in pregnancy from epidemiological, clinical and experimental studies [2-4].

Smoking in women has been shown to be detrimental to fertility [5], and to increase the maternal and fetal risks during pregnancy and the perinatal period [6]. Recent epidemiological reviews have suggested that smoking in pregnancy (SIP) increases the incidence of maternal complications such as placental abruption, placenta previa, ectopic pregnancy, prolonged rupture of membranes, inflammation of the umbilical cord, and amniotic fluid bacterial infections $[4,7,8]$. There is a well-established association between maternal smoking and reduced birth weight, which may lead to subsequent growth delay [4,911]. SIP is also associated with increased rates of postnatal respiratory infection, wheeze and otitis media $[12,13]$, as well as being an identified risk factor for sudden infant death syndrome [14-16]. Studies on the economic consequences of smoking during pregnancy suggest that smoking-attributable costs related to low birth weight is enormous, largely due to higher admission rates to neonatal intensive care units $[17,18]$. Studies also reported $66 \%$ higher medical costs for complicated births for smoking mothers compared to non-smoking mothers[19].

Maternal smoking during pregnancy may also have intergenerational effects. Kandel et al. [20] followed a sample of mothers who smoked during pregnancy for over 19 years, and showed higher rates of smoking among their female offspring, after adjustment for suspected confounders. It was suggested that maternal smoking may have had a biological effect, predisposing the fetus to nicotine dependence, and increasing the risk of daughters smoking [21].

Although recent studies suggest that the prevalence of SIP has been declining, it remains high in many countries, with between one in seven and one in three pregnant women in developed countries continuing to smoke $[22,23,10]$. In Canada, SIP rates were 30\% in Saskatoon and $32 \%$ in Nova Scotia in early 1990s, with the highest rates among low socio-economic status (SES) and younger mothers, and it declined to $17.8 \%$ (Southern Ontario) in 2001 [24-26]. British data suggest SIP rates declined from $37 \%$ in 1989 to $22.4 \%$ in 2005 [18,27]. US data suggest an overall rate slightly lower than this, with rates declining from $18.4 \%$ in 1990 to $11.4 \%$ in 2002 $[17,28]$.

Long term data from Finland estimated 22\% smoking in 1966, which declined to $18 \%$ in 1987 and ten years later it remained similar, with $15 \%$ of mothers smoking in $1997[28,29]$. Some evidence of a recent decline in preva- lence from $34 \%$ in the mid 1980 s to $22 \%$ in 1994 was reported in Norway [30].

SIP has been shown to be associated with education level, maternal age, social class and lack of private health insurance $[27,31,32]$. Typically a third of smokers report that they cut down or quit smoking during their pregnancy $[33,34]$, although the number who self-report that they smoke during pregnancy may be an underestimate of the true prevalence [35].

Smoking in pregnancy remains prevalent in Australia $[9,10]$, and further investigation of the correlates and population groups at risk are required to develop populationlevel targeted interventions. This paper reports data on prevalence and on the factors associated with smoking in pregnancy among all births in NSW between 1999 and 2003. This provides a large, comprehensive sample of women who delivered babies in the state, and was collected using a population-based surveillance system. The aims of this investigation were (i) to identify socio-demographic factors associated with smoking in pregnancy in NSW, (ii) to compare those who quit (smoking cessation) during pregnancy with those who continue, [iii] to compare the characteristics of heavy versus light smokers in late pregnancy, and [iv] to compare these results with smoking prevalence rates in general population surveys of all women of childbearing age. The study aims to identify the highest risk population segments, in order to develop group-specific interventions.

\section{Methods}

The data were the NSW Midwives Data Collection (MDC) 1999-2003, a surveillance system covering all births in NSW public and private hospitals, as well as home births. The MDC is administered by the NSW Health Department, and encompasses all live-births and stillbirths of at least 20 weeks gestation or at least 400 grams birthweight. It relies on the attending midwife to complete a notification form when a birth occurs. The form includes demographic items and items on maternal health, smoking, the pregnancy, labour, delivery and perinatal outcomes. The validation study on the NSW MDC system compared records of raw MDC as reported by hospitals with the hospital medical record [36]. Excellent levels of agreement were demonstrated for all the 44 data items studied. The majority of the data items had a $90 \%$ or more agreement.

Pregnant women were classified as smokers or non-smokers according to their self-reported smoking status during pregnancy. They were classified as 'smokers' if they ever smoked during the current pregnancy. Categories of tobacco use were based upon the reported quantity smoked in the second half of pregnancy: (1) quitters, who 
Table I: Socio-demographic determinants of smoking during pregnancy: percentage of smoking and adjusted odds ratios (AOR) from multiple logistic regression analysis

\begin{tabular}{|c|c|c|c|}
\hline Socio-demographic characteristics & Total number of women (\%) & $\%$ of smokers $(n=72,428)$ & ${ }^{\Psi}$ Adjusted odds ratio $(95 \% \mathrm{Cl})$ \\
\hline \multicolumn{4}{|l|}{ Year of delivery\# } \\
\hline 1999-2003 & $426344(100.0)$ & 17.0 & \\
\hline 1999 & $85655(20.2)$ & 19.0 & 1.00 \\
\hline 2000 & $86439(20.3)$ & 17.4 & $0.91(0.88-0.93)^{*}$ \\
\hline 2001 & $84362(19.8)$ & 17.1 & $0.87(0.85-0.89)^{*}$ \\
\hline 2002 & 84573 (19.8) & 16.4 & $0.83(0.81-0.85)^{*}$ \\
\hline 2003 & $85015(19.9)$ & 15.1 & $0.77(0.75-0.79)^{*}$ \\
\hline \multicolumn{4}{|l|}{ Maternal age (years)\# } \\
\hline Under 20 years & $18778(4.4)$ & 42.9 & $3.73(3.58-3.89)^{*}$ \\
\hline $20-34$ & $329834(77.4)$ & 16.9 & I.3। $(1.27-1.34)^{*}$ \\
\hline $35+$ & $77553(\mid 8.2)$ & 11.2 & 1.00 \\
\hline \multicolumn{4}{|l|}{ Aboriginal status\# } \\
\hline Non Aboriginal & $415583(97.5)$ & 16.0 & 1.00 \\
\hline Aboriginal & $10579(2.5)$ & 57.8 & $3.43(3.29-3.58)^{*}$ \\
\hline \multicolumn{4}{|l|}{ Parity\# } \\
\hline Primiparous & I77304 (4I.6) & 14.3 & 1.00 \\
\hline Multiparous & $24899 \mid(58.4)$ & 18.9 & $\mathrm{I} .49(\mathrm{I} .46-\mathrm{I} .5 \mathrm{I})^{*}$ \\
\hline \multicolumn{4}{|l|}{ Country of birth\# } \\
\hline Australian born & $309580(72.7)$ & 20.5 & 1.00 \\
\hline NZ and Oceania & $17809(4.2)$ & 18.9 & $0.75(0.72-0.78)^{*}$ \\
\hline UK \& Ireland & $12866(3.0)$ & 11.6 & $0.77(0.73-0.82)^{*}$ \\
\hline Other Europe & $11195(2.6)$ & 10.1 & $0.51(0.47-0.54)^{*}$ \\
\hline Middle East & $16864(4.0)$ & 8.3 & $0.25(0.24-0.27)^{*}$ \\
\hline Asia & $46721(11.0)$ & 1.8 & $0.066(0.06-0.07)^{*}$ \\
\hline America/Africa & $7313(1.7)$ & 5.2 & $0.24(0.22-0.26)^{*}$ \\
\hline Others & $3680(0.9)$ & 7.0 & $0.44(0.39-0.50)^{*}$ \\
\hline \multicolumn{4}{|l|}{ Socio-economic status (SES)\# } \\
\hline Lowest SES & $166987(39.5)$ & 22.3 & $3.33(3.23-3.43)^{*}$ \\
\hline Moderate SES & $|6866|(39.9)$ & 16.9 & $2.40(2.32-2.47)^{*}$ \\
\hline Highest SES & $87404(20.7)$ & 6.6 & 1.00 \\
\hline \multicolumn{4}{|l|}{ Booking in\# } \\
\hline Booked & $416223(97.6)$ & 16.5 & 1.00 \\
\hline Unbooked & $10120(2.4)$ & 36.7 & $1.52(1.44-1.61)^{*}$ \\
\hline \multicolumn{4}{|l|}{ Weeks at Ist antenatal visit\# } \\
\hline $0-12$ weeks & $245729(58.2)$ & 14.4 & 1.00 \\
\hline 13-26 weeks & $156396(37.0)$ & 18.6 & $1.45(1.42-1.47)^{*}$ \\
\hline 27 weeks + & $203 \mid 4(4.8)$ & 31.8 & $2.68(2.58-2.77)^{*}$ \\
\hline
\end{tabular}

\#Statistically significant $(p<0.05)$ in bivariate analyses; * ORs significant at $p<0.05$ level; ${ }^{\Psi}$ The fitted multiple logistic regression model is significant at $p<0.000$ I (Model Chi square $=44067.74, \mathrm{df}=20$ ), The model predicted overall $83.7 \%$ correctly classified (considering cut point 0.50 ). Dependent variable: Current smoking status (smoked yes $=I$, no smoking $=0$ ), Explanatory variables :Year of delivery, maternal age, Aboriginal status, parity, country of birth, SES, booking in and weeks of gestation at first antenatal care. For all variables not stated and missing cases excluded from the analyses.

reported smoking at the commencement of pregnancy, but did not smoke in the second half of pregnancy; (2) light smokers, reported 10 cigarettes or fewer per day; (3) heavy smokers, reported more than 10 cigarettes per day; and (4) smoking quantity unknown. Patients socio-economic status (SES) was constructed based on 'the Index of socio-economic disadvantage' calculated for NSW 2001 census population by postcode of residence. Firstly, all the postcodes for NSW MDC were ranked by index of socioeconomic disadvantage, and then grouped into five quintiles of SES from the lowest to the highest. Finally, these were grouped in to three SES categories: lowest SES (lowest and the second lowest quintiles of SES), moderate SES $\left(^{\text {rd }}\right.$ and $4^{\text {th }}$ quintiles of SES) and Highest SES (the $5^{\text {th }}$ quintile of SES).

Comparisons were carried out between these NSW MDC data and a representative population survey. This was the NSW Continuous Health Survey program 2002-2003, which asked a random sample of 25,630 NSW adults about a range of behaviours including smoking (NSW Continuous Health Survey 2002 onwards NSW Health 2004). Raw data from the NSW study was reanalysed, with females chosen only, and age groups 18 up to 20 years, 20-34, and 35-44 years to assess smoking prevalence. Weighted prevalence estimates were reported. 
Table 2: Defining the interactions among high risk groups for smoking in pregnancy in NSW

\begin{tabular}{|c|c|c|c|c|c|c|c|c|}
\hline & \multicolumn{8}{|c|}{ Percentage of smoking during pregnancy (SIP) } \\
\hline & \multicolumn{3}{|c|}{ Maternal age (years) } & \multicolumn{2}{|c|}{ Aboriginal status } & \multicolumn{3}{|c|}{ Weeks of gestation at Ist antenatal visit } \\
\hline & $<20$ years & $20-34$ & $35+$ & Aboriginal & Non-Aboriginal & $0-12$ & $13-26$ & $27+$ \\
\hline \multicolumn{9}{|l|}{ Maternal age (years) } \\
\hline$<20$ years & - & - & - & 60.5 & 40.5 & 43.0 & 41.6 & 44.7 \\
\hline $20-34$ & - & - & - & 56.7 & 15.9 & 14.3 & 18.3 & 31.4 \\
\hline $35+$ & - & - & - & 60.2 & 10.7 & 9.4 & 12.7 & 24.6 \\
\hline \multicolumn{9}{|l|}{ Aboriginal status } \\
\hline Aboriginal & 60.5 & 56.7 & 60.2 & - & - & 51.3 & 58.2 & 72.5 \\
\hline Non-Aboriginal & 40.5 & 15.9 & 10.7 & - & - & 13.6 & 17.6 & 28.7 \\
\hline \multicolumn{9}{|l|}{ Socio-economic status (SES) } \\
\hline Lowest SES & 42.8 & 21.5 & 17.4 & 59.8 & 20.7 & 20.1 & 22.1 & 34.4 \\
\hline Moderate SES & 43.7 & 16.6 & 11.5 & 55.1 & 16.0 & 14.5 & 18.8 & 32.1 \\
\hline Highest SES & 36.3 & 6.9 & 4.8 & 36.5 & 6.5 & 5.0 & 9.1 & 16.3 \\
\hline \multicolumn{9}{|l|}{ Country of birth } \\
\hline English speaking background & 45.7 & 19.8 & 13.5 & - & - & 16.1 & 23.9 & 45.0 \\
\hline Non-English speaking background & 10.3 & 4.9 & 4.8 & - & - & 3.8 & 5.2 & 9.4 \\
\hline \multicolumn{9}{|c|}{ Weeks of gestation at Ist antenatal visit } \\
\hline $0-12$ weeks & 43.0 & 14.3 & 9.4 & 51.3 & 13.6 & - & - & - \\
\hline 13-26 weeks & 41.6 & 18.3 & 12.7 & 58.2 & 17.6 & - & - & - \\
\hline 27 weeks + & 44.7 & 31.4 & 24.6 & 72.5 & 28.7 & - & - & - \\
\hline
\end{tabular}

Bivariate analyses were used to explore the associations between socio-demographic characteristics and smoking during pregnancy. Chi-square tests were used to test for statistical significance. Multiple logistic regression analyses were constructed to examine the relative contribution of each of the socio-demographic variables on smoking behaviour during pregnancy. Based on the initial analyses, factors placing groups at highest risk of smoking in pregnancy were further examined, to identify sub-groups at extreme risk in the population. Separate logistic regression models were constructed to examine factors associated with attempts at smoking cessation during pregnancy, and light versus heavy smokers. Adjusted odds ratios (OR) and 95\% confidence intervals (CI) were used, and the log likelihood and model chi square were used to examine the goodness-of-fit and adequacy of the logistic regression models.

\section{Results}

\section{Socio-demographic characteristics of smoking in pregnancy}

Of the 426,425 women confined in NSW 1999-2003, there were 426,344 women whose smoking status was recorded. Among them 72,428 were smokers (17.0\%), and 353,916 were non-smokers. The demographic characteristics of these women are presented by age, ethnicity, parity, socio-economic status and hospital booking for confinement (Table 1).
Only $4.4 \%$ of confinements were to mothers aged less than 20 years, and $18.2 \%$ were to those aged 35 years or older. The majority of the women were Australian born $(72.7 \%)$, followed by other ethnic groups. Of the women, $41.6 \%$ gave birth for the first time, $1.5 \%$ were unbooked for this confinement and $2.5 \%$ were of indigenous (Aboriginal) background (Table 1). Overall, more than half $(58.2 \%)$ of mothers attended their first antenatal visit in the first trimester of pregnancy, $37.0 \%$ in the second trimester and $4.8 \%$ attended in the third trimester.

The relationship between various maternal characteristics and smoking during pregnancy is shown in table 1 . The sample size for each subgroup is shown in the left hand column, and the smoking prevalence in the middle column. The adjusted odds ratios with $95 \%$ confidence interval $(95 \% \mathrm{CI})$ for smoking, compared to the reference group $(\mathrm{OR}=1.00)$ are shown in the right hand column. In $1999-2003,17 \%$ of the NSW mothers smoked during the pregnancy period and this rate declined from $19 \%$ in 1999 to $15.1 \%$ in 2003 . The results showed much higher rates of smoking during pregnancy among teenage mothers (42.9\% smoked), compared to older mothers over 35 years, of whom $11.2 \%$ smoked. Even among young teenage mothers aged 16 years or less, almost half smoked during pregnancy. High rates of smoking were reported by Aboriginal mothers (57.8\%), who were over three times as likely to smoke compared to non-Aboriginal mothers 
Table 3: Socio-demographic determinants of smoking cessation and heavy smoking during pregnancy: percentage of quit, \% of heavy smokers and adjusted odds ratios (AOR) from multiple logistic regression analysis

\begin{tabular}{|c|c|c|c|c|c|}
\hline $\begin{array}{l}\text { Socio-demographic } \\
\text { characteristics }\end{array}$ & $\begin{array}{l}\text { Total number of } \\
\text { smokers }\end{array}$ & $\begin{array}{c}\% \text { of smokers quit } \\
\text { smoking }(n=2,920)\end{array}$ & $\begin{array}{c}\text { }{ }^{\Psi} \text { Adjusted odds ratio } \\
(95 \% \mathrm{Cl})\end{array}$ & $\%$ of heavy smokers & 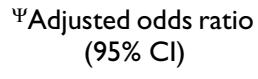 \\
\hline \multicolumn{6}{|l|}{ Year of delivery\# } \\
\hline 1999-2003 & 69500 & 4.0 & & 49.6 & \\
\hline 1999 & 16302 & 4.5 & 1.00 & 52.2 & 1.00 \\
\hline 2000 & 15000 & 4.1 & $0.92(0.83-1.04)$ & 49.7 & $0.90(0.86-0.94)^{*}$ \\
\hline 2001 & 14422 & 4.0 & $0.92(0.82-1.03)$ & 49.6 & $0.89(0.85-0.93)^{*}$ \\
\hline 2002 & 13820 & 4.0 & $0.94(0.83-1.05)$ & 48.9 & $0.85(0.8 \mathrm{I}-0.89)^{*}$ \\
\hline 2003 & 12875 & 3.3 & $0.77(0.68-0.87)^{*}$ & 46.8 & $0.78(0.76-0.82)^{*}$ \\
\hline \multicolumn{6}{|l|}{ Maternal age (years)\# } \\
\hline Under 20 years & 8063 & 3.9 & $0.84(0.7 I-0.99)^{*}$ & 45.4 & 1.00 \\
\hline $20-34$ & 55625 & 4.1 & $1.11(0.98-1.26)$ & 49.6 & 1.01 (0.95-1.06) \\
\hline $35+$ & 8705 & 3.6 & 1.00 & 53.0 & $1.18(1.10-1.27)^{*}$ \\
\hline \multicolumn{6}{|l|}{ Aboriginal status\# } \\
\hline Non Aboriginal & 66287 & 4.3 & $1.86(1.51-2.30)^{*}$ & 48.7 & 1.00 \\
\hline Aboriginal & 6112 & 1.6 & 1.00 & 58.6 & $1.24(1.17-1.31)^{*}$ \\
\hline \multicolumn{6}{|l|}{ Parity\# } \\
\hline Primiparous & 25407 & 6.8 & $2.55(2.34-2.77)^{*}$ & 40.2 & 1.00 \\
\hline Multiparous & 47007 & 2.6 & 1.00 & 54.4 & $1.68(1.62-1.73)^{*}$ \\
\hline \multicolumn{6}{|l|}{ Country of birth\# } \\
\hline Australian born & 63519 & 4.0 & 1.00 & 50.7 & 1.00 \\
\hline NZ and Oceania & 3374 & 3.4 & $0.94(0.77-1.14)$ & 41.3 & $0.61(0.57-0.66)^{*}$ \\
\hline UK \& Ireland & 1488 & 4.7 & $0.90(0.70-1.16)$ & 47.6 & $0.94(0.84-1.04)$ \\
\hline Other Europe & 1129 & 4.1 & $0.83(0.6 \mathrm{I}-\mathrm{I} . \mathrm{I} 2)$ & 40.4 & $0.68(0.60-0.78)^{*}$ \\
\hline Middle East & 1406 & 2.8 & $0.87(0.63-1.21)$ & 41.3 & $0.56(0.5 \mathrm{I}-0.64)^{*}$ \\
\hline Asia & 822 & 10.9 & $2.71(2.15-3.43)^{*}$ & 28.1 & $0.37(0.3 \mathrm{I}-0.44)^{*}$ \\
\hline America/Africa & 380 & 7.4 & $1.38(0.91-2.1)$ & 35 & $0.56(0.44-0.69)^{*}$ \\
\hline Others & 258 & 5.6 & $1.00(0.57-1.76)$ & 45.9 & $0.89(0.69-1.17)$ \\
\hline \multicolumn{6}{|l|}{ SES\# } \\
\hline Lowest SES & 37289 & 3.1 & 1.00 & 52.7 & $1.84(1.72-1.96)^{*}$ \\
\hline Moderate SES & 28485 & 3.8 & $1.11(1.02-1.21)^{*}$ & 48.0 & $1.58(1.48-1.68)^{*}$ \\
\hline Highest SES & 5797 & 10.2 & $2.79(2.5 \mathrm{I}-3.10)^{*}$ & 35.8 & 1.00 \\
\hline Booking in\#: Booked & 68710 & 4.2 & $1.83(1.33-2.53)^{*}$ & 48.9 & 1.00 \\
\hline Unbooked & 3710 & 1.3 & 1.00 & 62.0 & $1.20(1.10-1.31)^{*}$ \\
\hline \multicolumn{6}{|l|}{ Weeks at Ist antenatal visit\# } \\
\hline $0-12$ weeks & 35263 & 5.0 & $2.33(1.91-2.85)^{*}$ & 46.7 & 1.00 \\
\hline 13-26 weeks & 29084 & 3.6 & $1.75(1.42-2.14)^{*}$ & 50.1 & $1.17(1.13-1.21)^{*}$ \\
\hline 27 weeks + & 6453 & 1.7 & 1.00 & 58.3 & $1.55(1.47-1.66)^{*}$ \\
\hline Any obstetric condition\#: No & 67272 & 3.9 & 1.00 & 48.9 & 1.00 \\
\hline Yes & 5148 & 5.4 & $1.19(1.04-1.35)^{*}$ & 62.0 & $1.20(1.10-1.31)^{*}$ \\
\hline
\end{tabular}

\#Statistically significant $(p<0.05)$ in bivariate analyses; * ORs significant at $p<0.05$ level; The fitted multiple logistic regression model is significant at $\mathrm{p}<0.00$ I; The model predicted overall $95.9 \%$ correctly classified (considering cut point 0.50 ). For all variables not stated and missing cases excluded from the analyses.

(OR $=3.43$, 95\%CI: 3.29-3.58). On the other hand, overseas-born mothers showed low to very low rates of smoking. Compared with the $20.5 \%$ rate among Australia-born women, all immigrant women were less likely to smoke, with only $1.8 \%$ among Asian born women (Odds Ratio = $0.06)$.

Multiparity, lower socio-economic status, unbooked confinements, and lack of antenatal care in the first trimester were other factors significantly and independently associ- ated with increased risk of maternal smoking during pregnancy.

\section{Identifying sub-groups at extreme risk}

Based on the analyses in table 1, the three groups at highest risk of smoking in pregnancy were younger mothers, indigenous, and late antenatal care attenders. These three groups are examined in table 2, exploring further the interactions between them, in order to identify the highest risk sub-groups. Although there was a strong dose response gradient in SIP rates by age among non-Aborigi- 


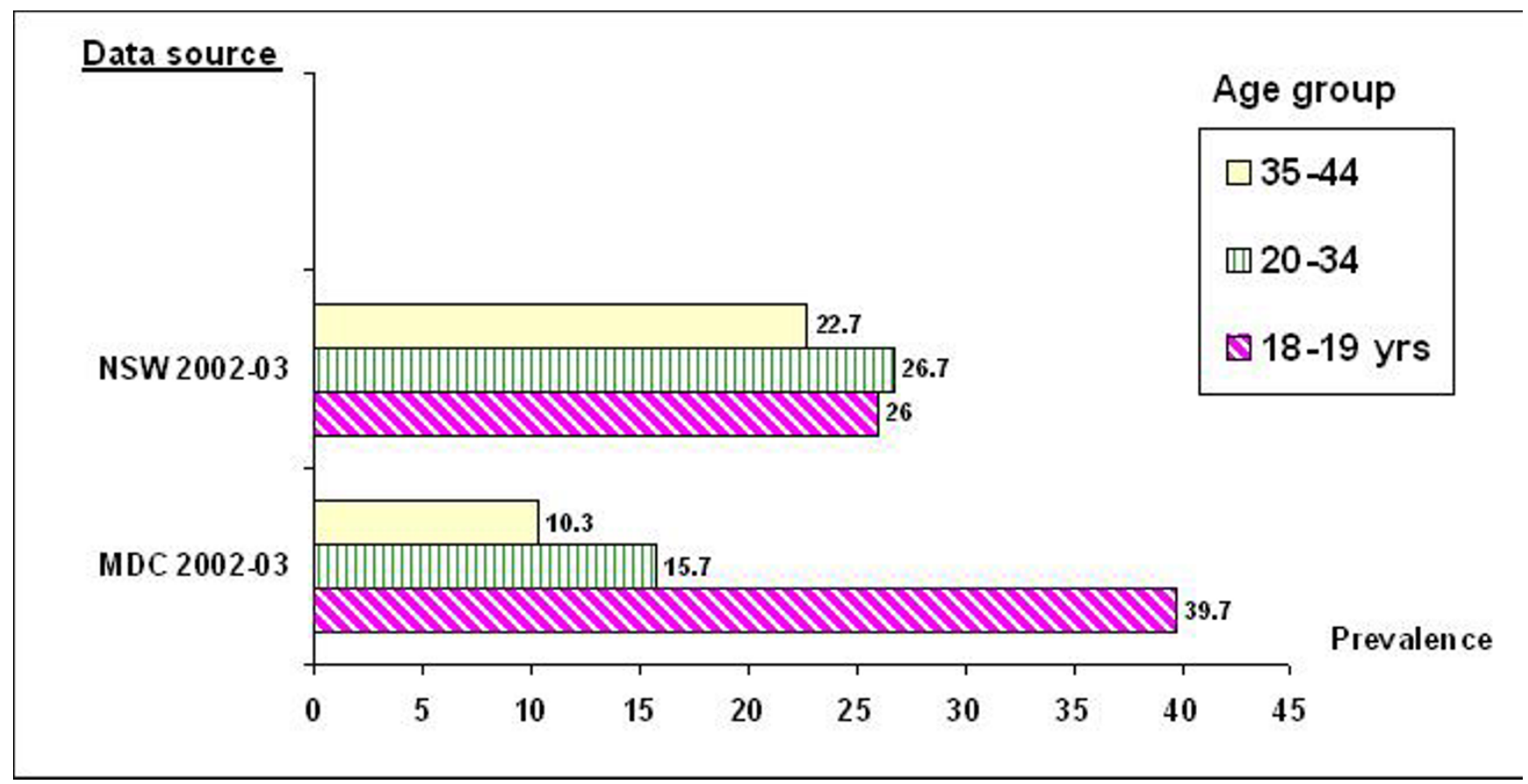

Figure I

Comparisons of smoking prevalence among women of childbearing age: smoking during pregnancy from the NSW MDC (20022003) compared to women from population samples from NSW continuous health surveys (2002-2003)

nal mothers, this age-relationship was much less apparent among Aboriginal mothers, where SIP rates ranged from $56.7 \%$ to $60.5 \%$ by age. For early (<12 weeks) antenatal care attenders, there was a strong relationship with age (a fourfold decrease in SIP rates across age groups), but for those attending antenatal care latest, there was much less of a gradient. There was a three to fourfold gradient in SIP rates between Aboriginal and non-Aboriginal mothers, irrespective of antenatal care attendance. By socio-economic status, the gradient in SIP prevalence was greatest for older mothers, and least for teenage mothers, and the gradient was greater among non-Aboriginal mothers compared to Aboriginal mothers. There were relatively fixed differentials between English speaking and non-English speaking background mothers, irrespective of age or antenatal care.

\section{Smoking cessation (quit) and amount smoked during pregnancy}

Among the 72,428 pregnant women who identified themselves as smokers, 2,920(4.0\%) reported quitting during pregnancy and this rate declined from $4.5 \%$ in 1999 to $3.3 \%$ in 2003. The prevalence rates and odds ratios for various maternal characteristics associated with smoking cessation during pregnancy are shown in table 3. The following factors were significantly associated with an increased likelihood of smoking cessation during pregnancy: mothers who were born in Asia, first time mothers, higher SES group, those who reported early attendance for antenatal care and those with any obstetric complication.

Although no questions were asked about tobacco reduction, all smokers were asked about the amount they smoked during pregnancy. Smokers were classified as heavy smokers ( $>10$ cigarettes per day), or light smokers (smoked less than 10 daily) and \% of heavy smokers by socio-demographic characteristics are shown in Table 3. Of the total smokers 34,318 (50.4\%) reported to be light smokers and 33720 (49.6\%) were heavy smokers and those whose quantity of smoking were unknown are excluded. Although smoking rates among older mothers (35+ years) were lower, they were more likely to be heavy smokers than teenage mothers (53\% vs. $45.4 \%$ ). This difference was significant in univariate analysis, and $18 \%$ more likely in the adjusted analysis ( $\mathrm{p}<0.05)$. Heavy smoking was more likely among Aboriginal mothers, in those with lower SES, multiparous, unbooked mothers and late antenatal care attenders. The highest proportion of heavy smokers was among unbooked mothers who smoked (62\%) and the lowest were among the Asian women $(28.1 \%)$.

\section{Comparisons with general population surveys}

The analysis between MDC women 2002-2003 and age matched women from general population surveys (NSW continuous health surveys 2002-2003) are shown in fig- 
ure 1 . Teenage smoking in pregnancy data from the MDC were confined to those aged 18-19 years for age group comparability with the general population surveys. Teenage smoking in pregnancy was much higher (39.7\%) than general sample of age matched NSW data (26\%). For mothers aged 20-34 or 35 and older, smoking rates in pregnancy were typically about a third lower than smoking rates among age matched women in the general community, suggesting that about a third might have quit before or early in pregnancy.

\section{Discussion}

This study explored the socio-demographic characteristics of women who continue to smoke during pregnancy. In 1999-2003, 17\% of all NSW pregnant women smoked during their pregnancy period and it declined from 19\% in 1999 to $15.1 \%$ in 2003. Previous studies on NSW reported more than one-fifth of the pregnant women smoked during pregnancy period $[4,10]$. Although the prevalence of smoking during pregnancy has been declining, it remains a significant public health concern. The findings showed that maternal social and demographic characteristics were significantly associated with smoking behaviour. The smoking rate was worryingly high among teenage mothers, a finding consistent with previous studies in NSW and overseas [10,27]. The highest-risk group analyses suggest that strongest influencers for SIP might include maternal age and indigenous status, with half of some of these subgroups reporting smoking in pregnancy, a rate four times the general population level.

On the other hand, overseas-born mothers showed low to very low rates of smoking, and based on the data in table 2 , a protective effect independent of maternal age. Multiparity, lower SES, unbooked confinements, and lack of antenatal care in the first trimester were other factors significantly and independently associated with increased risk of maternal smoking during pregnancy. Similar to the Canadian study, pregnant smokers in this study were more likely to begin prenatal care in the second or third trimester, or to receive no care at all [24-26]. These socioeconomic markers identify groups at risk of sub optimal antenatal care, of which smoking is one important indicator [37].

About $4 \%$ of women reported that they may quit smoking during pregnancy. Mothers who were born in Asia, first time mothers, those who were of higher SES and those who reported early attendance for antenatal care reported an increased likelihood of smoking cessation during pregnancy: Heavy smoking (more than 10 cigarettes) was common among older mothers (aged over 35). The later group may reflect greater duration of nicotine exposure and greater dependence. The results also showed that Aboriginal mothers, lower SES, multiparous, unbooked mothers and late antenatal care attenders were more likely to be heavy smokers. The results showed that over the years, the rate of smoking during pregnancy and proportion of heavy smokers declined. From these findings one might expect the rate of intention to quit to increase, but the reverse was observed, as the rate of quitting also declined.

The analysis between MDC women and age matched women from general population surveys showed that teenage smoking in pregnancy was much higher than general sample age matched NSW data. This suggests substantial differences, in that teenagers who become pregnant are risk takers (and also at increased risk for alcohol and other drug usage) [38]. It suggests that smoking in pregnancy, among teenage mothers, may be a marker of broader health compromising risk taking, which may have adverse maternal and infant effects. For mothers aged 20-34 or 35 and older, smoking rates in pregnancy were typically about a third lower than smoking rates among age matched women in the general community, suggesting that about a third might have quit before or early in pregnancy.

About $20 \%$ to $40 \%$ of women quit smoking on their own initiative when they realise they are pregnant [39]. However, there remains a large proportion of pregnant smokers who are unable to quit. It is clear that smoking cessation is a complex undertaking which requires specific skills [40].

Kendrick et al. [41] randomly assigned clinics to intervention or control status across three states, and observed higher self-reported quitting among intervention clinics. However, the cotinine verified quit rates were not significantly different. This study highlighted that pregnant smokers may react to smoking cessation counselling by giving the desired response to questions at follow-up, and the difficulties in integrating such a program in public prenatal clinics where existing staff were already busy. Another study [42] reported that adding individual smoking cessation counselling did not increase quitting rates during pregnancy. Apart from the materials used in various interventions, partners of the pregnant smokers may have played a role in successful smoking cessation. Women who have a non-smoking partner, or living in a non-smoking household, or encouraged by their partners to stop smoking, were found to have a strong association with successful cessation $[43,44]$. There are challenges in contributing to further effective smoking cessation interventions, which may need to be specifically targeted at the sub-groups identified here.

A previous study in Australia estimated that if smoking were eliminated, $19.8 \%$ of the total low birth-weight inci- 
dence, $7.8 \%$ of the preterm births and 3.6\% of admission require to special care nursery or neonatal intensive care unit (SCN/NICU) would have been prevented [4]. Researchers have re-iterated identified the poor obstetric outcomes for women who smoked during the pregnancy $[4,9-11,45,46]$, making investment in exploring SIP interventions a public health priority. However, the remaining smokers may be difficult to change, and interventions may require larger effect sizes than have been produced to date [47].

\section{Conclusion}

The social environment, and individual level demographic attributes are shown to be significantly associated with smoking behaviour and quitting smoking during pregnancy. More innovative system wide approaches to smoking in pregnancy are required, especially among teenage mothers, those at social disadvantage or those from an Aboriginal background. The information provided in this paper challenges policy makers to develop innovative interventions for those at highest risk.

\section{Competing interests}

The author(s) declare that they have no competing interests.

\section{Authors' contributions}

$\mathrm{MM}$ was responsible for data analysis and led the writing of the manuscript. MM and AEB drafted and revised the manuscript.

\section{Acknowledgements}

The authors are grateful to the Centre for Epidemiology and Research, NSW Department of Health, for providing access to the NSW MDC data.

\section{References}

I. Sontag LW, Wallace RF: The effects of cigarette smoking during pregnancy upon the fetal heart rate. Am J Obstet Gynecol 1935, 29:77-83.

2. Adams EK, Melvin CL: Costs of maternal conditions attributable to smoking during pregnancy. Am J Prev Med 1998, 15(3):212-219.

3. Castles A, Adams EK, Melvin CL: Effects of smoking during pregnancy - five meta analyses. Am J Prev Med 1999, 16:208-2 I5.

4. Wong PL, Bauman A: How well does epidemiological evidence hold for the relationship between smoking and adverse obstetric outcomes in New South Wales? Aust NZJ Obstet Gynaecol 1997, 37(2):168-173.

5. Baird DD, Wilcox AJ: Cigarette smoking associated with delayed conception. JAMA I 985, 253(20):2979-83.

6. Ates $U, A$ ta $B$, Armagan $F$, Has R, Sidal B: Acute effects of maternal smoking on fetal hemodynamics. Int J Gynaecol Obstet 2004, 87(I): 14-18.

7. Ashfaq M, Janjua MZ, Nawaz M: Effects of maternal smoking on placental morphology. J Ayub Med Coll Abbottabad 2003, I5(3): I2-15.

8. Bouyer J, Coste J, Shojaei T, Pouly JL, Fernandez H, Gerbaud L, JobSpira N: Risk factors for ectopic pregnancy: a comprehensive analysis based on a large case-control, population-based study in France. Am J Epidemiol 2003, 157(3): 185-94. Review.

9. Chan A, Keane RJ, Robinson JS: The contribution of maternal smoking to preterm birth, small for gestational age and low birthweight among Aboriginal and non-Aboriginal births in South Australia. Med J Aust 200I, 174(8):389-93.

10. Mohsin M, Wong F, Bauman A, Bai J: Maternal and neonatal factors influencing premature birth and low birth weight in Australia. J Biosoc Sci 2003, 35(2):161-74.

II. Ojima T, Uehara R, Watanabe M, Tajimi M, Oki I, Nakamura Y: Population attributable fraction of smoking to low birth weight in Japan. Pediatr Int 2004, 46(3):264-7.

12. Hofhuis W, de Jongste JC, Merkus PJ: Adverse health effects of prenatal and postnatal tobacco smoke exposure on children. Arch Dis Child 2003, 88( I 2): 1086-90. Review.

13. Hoo AF, Henschen M, Dezateux C, Costeloe K, Stocks J: Respiratory function among preterm infants whose mothers smoked during pregnancy. Am J Respir Crit Care Med 1998, I 58(3):700-5.

14. Anderson ME, Johnson DC, Batal HA: Sudden Infant Death Syndrome and prenatal maternal smoking: rising attributed risk in the Back to Sleep era. BMC Med 2005, 3(1):4.

15. Chong DS, Yip PS, Karlberg J: Maternal smoking: an increasing unique risk factor for sudden infant death syndrome in Sweden. Acta Paediatr 2004, 93(4):47I-8.

16. Horne RS, Franco P, Adamson TM, Groswasser J, Kahn A: Influences of maternal cigarette smoking on infant arousability. Early Hum Dev 2004, 79(I):49-58. Revie.

17. Adams EK, Miller VP, Ernst C, Nishimura BK, Melvin C, Merritt R: Neonatal health care costs related to smoking during pregnancy. Health Econ 2002, I I(3): 193-206.

18. Petrou S, Hockley C, Mehta Z, Goldacre M: The association between smoking during pregnancy and hospital inpatient costs in childhood. Soc Sci Med 2005, 60(5): $107 \mid-85$.

19. Orleans CT, Johnson RW, Barker DC, Kaufman NJ, Marx JF: Helping pregnant smokers quit: meeting the challenge in the next decade. West J Med 200I, 174(4):276-8I.

20. Kandel DB, Wu P, Davies M: Maternal smoking during pregnancy and smoking by adolescent daughters. Am J Public Health 1994, 84(9): | 407-13.

21. Benowitz N, Dempsey D: Pharmacotherapy for smoking cessation during pregnancy. Nicotine Tob Res 2004:S 189-202.

22. Cnattingius S: The epidemiology of smoking during pregnancy: smoking prevalence, maternal characteristics, and pregnancy outcomes. Nicotine Tob Res 2004:SI25-40. Review.

23. Colman GJ, Joyce T: Trends in smoking before, during, and after pregnancy in ten states. Am J Prev Med 2003, 24(I):29-35.

24. Dodds $L$ : Prevalence of smoking among pregnant women in Nova Scotia from 1988 to I992. CMA] 1995, 152(2): |85-90.

25. Johnson IL, Ashley MJ, Reynolds D, Goettler F, Lee-Han H, Stratton J, Yim C, Murray J: Prevalence of smoking associated with pregnancy in three Southern Ontario Health Units. Can J Public Health 2004, 95(3):209-13.

26. Muhajarine N, D'Arcy C, Edouard L: Prevalence and predictors of health risk behaviours during early pregnancy: Saskatoon Pregnancy and Health Study. Can J Public Health 1997, 88(6):375-9.

27. Penn G, Owen L: Factors associated with continued smoking during pregnancy: analysis of socio-demographic, pregnancy and smoking-related factors. Drug Alcohol Rev 2002, 2 I (I): 17-25.

28. Centers for Disease Control and Prevention (CDC): Smoking during pregnancy - United States, 1990-2002. MMWR Morb Mortal Wkly Rep 2004, 53(39):91I-5.

29. Isohanni M, Oja H, Moilanen I, Koiranen M, Rantakallio P: Smoking or quitting during pregnancy: associations with background and future social factors. Scand J Soc Med 1995, 23(1):32-8.

30. Eriksson KM, Salvesen KA, Haug K, Eik-Nes SH: Smoking habits among pregnant women in a Norwegian county 1987-1994. Acta Obstet Gynecol Scand 1996, 75(4):355-9.

31. Jaakkola N, Jaakkola MS, Gissler M, Jaakkola JJ: Smoking during pregnancy in Finland: determinants and trends, 1987-1997. Am J Public Health 200I, 9 I (2):284-6.

32. Forrest D, Horsley S, Roberts E, Barrow S: Factors relating to smoking and pregnancy in the North Western Region. J Public Health Med 1995, 17(2):205-10.

33. Ramsey AM, Blose D, Lorenz D, Thomas W, DePersio SR, Bruce FC: Cigarette smoking among women in Oklahoma: before, during, and after pregnancy. J Okla State Med Assoc 1993, 86(5):231-6. 
34. Tappin DM, Ford RP, Schluter PJ: Smoking during pregnancy measured by population cotinine testing. N Z Med J 1997, I I 0( I 050):3I I-4.

35. Ford RP, Tappin DM, Schluter PJ, Wild CJ: Smoking during pregnancy: how reliable are maternal self reports in New Zealand? J Epidemiol Community Health I997, 5 I (3):246-5 I.

36. Pym M, Taylor L: Validation Study of the New South Wales Midwives Data Collection. NSW Public Health Bulletin Supplement 1990, Number 8:

37. Rome ES, Rybicki LA, Durant RH: Pregnancy and other risk behaviors among adolescent girls in Ohio. J Adolesc Health 1998, 22(I):50-5.

38. Kramer MS, Seguin L, Lydon J, Goulet L: Socio-economic disparities in pregnancy outcome: why do the poor fare so poorly? Paediatr Perinat Epidemiol 2000, I4(3): 194-210.

39. Mas R, Escriba V, Colomer C: Who quits smoking during pregnancy? Scand J Soc Med 1996, 24(2): 102-6.

40. Campion P, Owen L, McNeill A, McGuire C: Evaluation of a mass media campaign on smoking and pregnancy. Addiction 1994, 89(10):1245-54.

4I. Kendrick JS, Zahniser SC, Miller N, Salas N, Stine J, Gargiullo PM, Floyd RL, Spierto FW, Sexton M, Metzger RW, et al.: Integrating smoking cessation into routine public prenatal care: the Smoking Cessation in Pregnancy project. Am J Public Health 1995, 85(2):217-22.

42. Secker-Walker RH, Solomon LJ, Flynn BS, Skelly JM, Lepage SS, Goodwin GD, Mead PB: Individualized smoking cessation counseling during prenatal and early postnatal care. Am J Obstet Gyneco 1994, I 7 I(5): I347-55.

43. Haug K, Aaro LE, Fugelli P: Smoking habits in early pregnancy and attitudes towards smoking cessation among pregnant women and their partners. Fam Pract 1992, 9(4):494-9.

44. Mabbutt J, Bauman A, Mohsin M: Letter, Partner smoking and the risk of smoking in pregnancy. Australian and New Zealand Journal of Public Health 2002, 26(6):57I-572.

45. Williams MA, Mittendorf R, Stubblefield PG, Lieberman E, Schoenbaum SC, Monson RR: Ciggarettes, coffee, and preterm premature rupture of the membranes. Am J Epidemiol 1992, 135:895-903.

46. Duffus CM, MacGillivray I: The incidence of pre-eclamptic toxaemia in smokers and non-smokers. Lancet 1968, 1:994-995.

47. Lumley J, Oliver S, Chamberlain C, Oakley L: Interventions for promoting smoking cessation during pregnancy [Review]. Cochrane Database of Systematic reviews, Published in the Cochrane Library 2005.

\section{Pre-publication history}

The pre-publication history for this paper can be accessed here:

http://www.biomedcentral.com/1471-2458/5/138/pre

pub http.//www.biomedcentral.com/1471-2458/5/138 